\title{
Hygrobates (Hygrobates) capillus sp. nov. (Arachnida: Acari: Hydrachnidia: Hygrobatidae) from South-central Honshu, Japan, with Records of Two Allied Species
}

\author{
Noriko Matsumoto, Hiroshi Kajihara and Shunsuke F. Mawatari \\ Division of Biological Sciences, Graduate School of Science, \\ Hokkaido University, Sapporo, 060-0810 Japan \\ E-mail:noriko-m@sci.hokudai.ac.jp (NM); kazi@sci.hokudai.ac.jp (HK); \\ shunfm@sci.hokudai.ac.jp (SFM)
}

(Received 13 July 2004; Accepted 12 January 2005)

\begin{abstract}
Three similar species of water mite in the subgenus Hygrobates (genus $H y$ grobates) are reported from middle Honshu, Japan. These include two recently described lacustrine species, Hygrobates (Hygrobates) biwaensis Tuzovskij, 2003 and $H$. (H.) rarus Tuzovskij, 2003, which are known only from Lake Biwa, and one new fluvial species, $H$. $(H$.) capillus sp. nov. The new species is distinguished from the other two by the truncate P-2 ventral projection; the female genital plates being longer than the genital opening and extending to the post-genital sclerite; the anterior border of the flat male genital plate; and the larger body size $(408-603 \mu \mathrm{m})$. Two or three setae are confirmed to be present on the female pre-genital sclerites in the three species reported herein; this character state has never so far been recorded in any member of this subgenus.

Key Words: Hydrachnidia, water mites, new species, central Japan, freshwater, fine structure, taxonomy, scanning electron microscopy.
\end{abstract}

\section{Introduction}

Most species of Hygrobates Koch, 1837, one of the largest genera of the watermite family Hygrobatidae, occur in still or slowly flowing waters, such as lakes, ponds, and the middle and lower reaches of rivers. They live among vegetation and between or underneath rocks. Among the 11 subgenera of this genus (Cook 1974; Tuzovskij and Gerecke 2003), the nominal subgenus Hygrobates is characterized by having in both sexes three pairs of genital acetabula that typically lie on the acetabular plates; the gonopore in males completely surrounded by sclerotization including the acetabular plates, but in females with pre- and post-genital sclerites and separated genital plates; legs showing no sexual dimorphism; and glandularia present on the fourth coxae and located near the suture between the third and fourth coxae (Cook 1974). The subgenus Hygrobates is distributed worldwide, with a global diversity of more than 110 species (Viets 1987).

Eleven species of the subgenus Hygrobates have been reported from Japan, viz., $H$. (H.) biwaensis Tuzovskij, 2003; $H$. (H.) calliger Piersig, 1896; $H$. (H.) foreli (Lebert, 1874); H. (H.) heteropalpis Imamura, 1954; $H$. (H.) japonicus Uchida, 1931; $H$. (H.) longipalpis (Hermann, 1804); H. (H.) longiporus Thor, 1898; H. (H.) minutus 
Imamura, 1953; H. (H.) papillosus Imamura, 1953; H. (H.) rarus Tuzovskij, 2003; and $H$. (H.) sinensis Uchida and Imamura, 1951 (Uchida 1931, 1934; Enami 1940; Imamura 1950, 1953a, 1953b, 1954, 1955, 1960, 1965, 1980, 1986; Imamura and Kikuchi 1986; Tuzovskij 2003).

A recent faunal survey of water mites conducted by the first author in southcentral Honshu, Japan, yielded three species of the subgenus Hygrobates, including one undescribed species, which is described herein. In this paper we also describe a new character that is shared by the new species and its congeners $H$. $(H$.) biwaensis and $H$. (H.) rarus.

\section{Material and Methods}

The specimens examined in this study were collected by the first author at six localities across south-central Honshu Island, Japan (Fig. 1). Qualitative sampling was conducted in rivers and lakes with a net of $250 \mu \mathrm{m}$ mesh size. Specimens were fixed and preserved in Koenike's fluid or fixed in $10 \%$ formalin and subsequently preserved in Koenike's fluid. Some specimens were dissected in lactic acid and mounted in polyvinyl alcohol or Euparal ${ }^{\mathrm{R}}$.

Observations and measurements were made with a differential interference contrast microscope (Olympus BH-2) and a scanning electron microscope (Hitachi $\mathrm{S}-2250 \mathrm{~N})$. Specimens for SEM observation were dehydrated in a graded series of

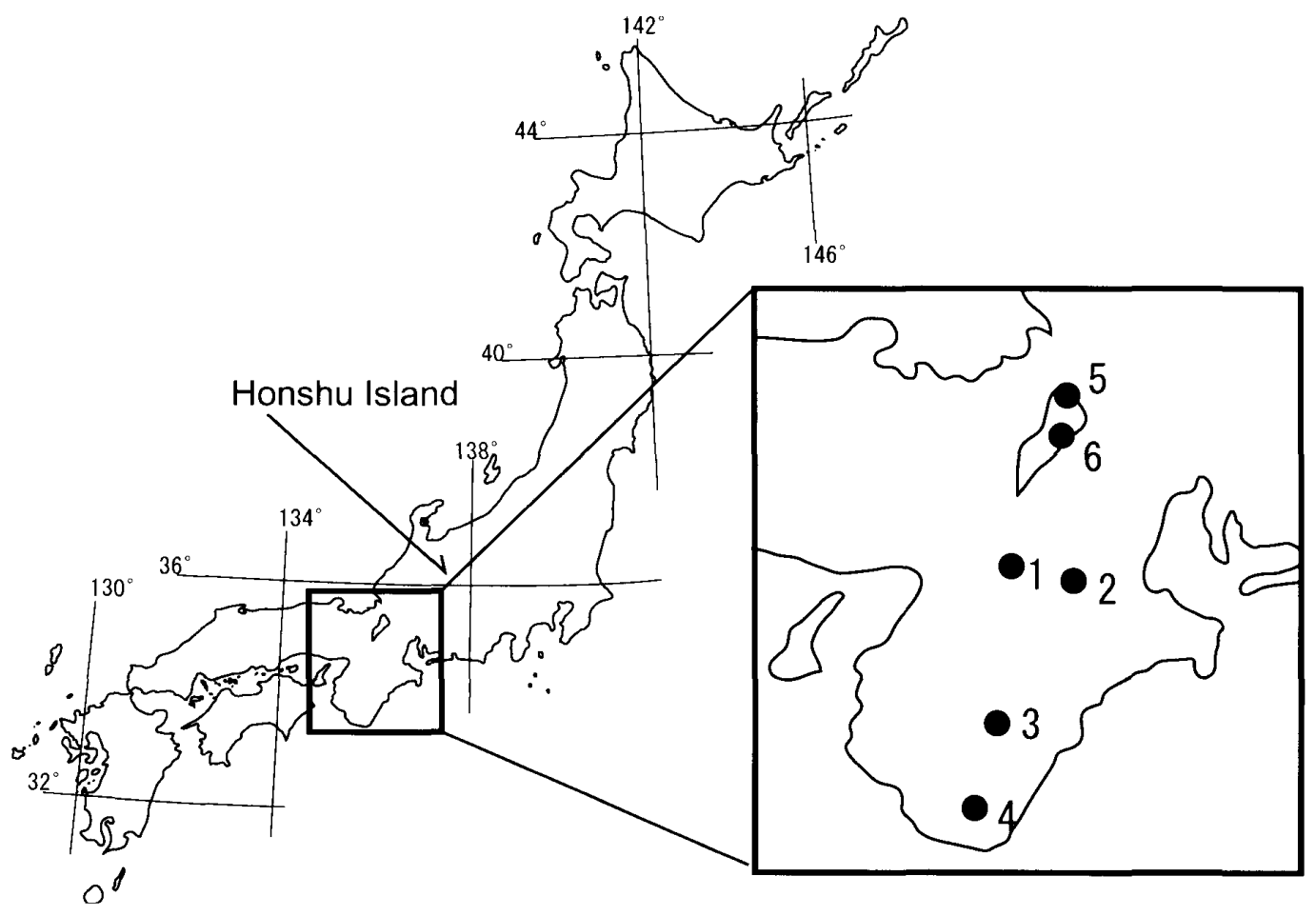

Fig. 1. Map of Japan showing the collecting sites. 1, Kizu River, Kyotanabe, Kyoto Prefecture; 2, Nabari River, Nabari, Mie Prefecture; 3, Kumano River, Hongu, Wakayama Prefecture; 4, Koza River, Kozagawa, Wakayama Prefecture; 5, Lake Biwa, Sugaura, Nishiazai, Shiga Prefecture; 6, Lake Biwa, mouth of Inugami River, Hikone, Shiga Prefecture. 
ethanol, saturated with hexamethyldisilazane $\left[\left(\mathrm{CH}_{3}\right)_{3} \mathrm{Si}\right]_{2} \mathrm{NH}$, dried in air, and sputter-coated with gold with an ion sputtering device (Hitachi E102). Drawings were prepared with the aid of a camera lucida.

Terminology follows Smith et al. (2001). Abbreviations are as follows. Palp: P-1, P-2, P-3, P-4, and P-5, proximal to distal segments. Genital acetabula: Ac1, anterior acetabulum; Ac2, medial acetabulum; Ac3, posterior acetabulum. Legs: I-L, first leg; II-L, second leg; III-L, third leg; IV-L, fourth leg. Leg segments: abbreviated as leg number followed by segment number from 1 to 6 , proximal to distal; e.g., distalmost segment (tarsus) of first leg is I-L-6. Coxal plates: CxI to CxIV, anterior to posterior.

Measurements are given in micrometers. Measurements of paired structures were made on only one member of the pair, haphazardly selected as to left or right. Where measurements were taken from multiple specimens, the measurement of the holotype or allotype is listed first, followed in parentheses by the mean, range, and number $(n)$ of paratype specimens measured. The number of specimens measured does not always equal the number of specimens examined because sometimes structures were missing or damaged. Width of idiosoma is given as maximum width of the posterior coxal group. The ratio of the distance between the insertion of the two ventral setae on P-4 to P-4 segment length is abbreviated as the "P-4 setae ratio". The ratio of lengths of L-5 and the longest terminal seta on it, on I-L to IV-L, is called the "seta to tibia ratio". L, when it is used by itself, stands for length, W for width, and $\mathrm{H}$ for height.

Type and voucher specimens are deposited in the Hokkaido University Museum (HUM), Sapporo, Japan, with catalog numbers prefaced by "ZIHU-"; the National Science Museum (NSMT), Tokyo, Japan, with catalog numbers prefaced by "NSMT-Ac-"; and the Lake Biwa Museum (LBM), Kusatsu, Shiga, Japan, with accession numbers.

\section{Taxonomy}

Hygrobates (Hygrobates) biwaensis Tuzovskij, 2003

(Fig. 2A)

Hygrobates (Hygrobates) biwaensis Tuzovskij, 2003: 1325-1329, figs 1-4.

Type locality. Kitakomatsu, Lake Biwa (Tuzovskij 2003).

Material examined. All specimens were collected from Lake Biwa at Sugaura, Nishiazai, Shiga Prefecture, on 4 Nov. 2000. Two males (NSMT-Ac 11701, ZIHU-2320) and four females (NSMT-Ac 11702, ZIHU-2321, 63080, 63081), dissected and mounted in Euparal ${ }^{\mathrm{k}}$. Three males (ZIHU-63079, NSMT-Ac 11700, LBM Misc. Invert. FY2004-2) and two females (NSMT-Ac 11703, LBM Misc. Invert. FY2004-2), dissected and mounted in polyvinyl alcohol. Two males (ZIHU-2322, 2323), two females (ZIHU-2324, 2325), and two nymphs (ZIHU-2326, 2327) in Koenike's fluid, all whole specimens. One male (ZIHU-2328) and one female (ZIHU-2329, 3064), metalcoated for SEM.

Remarks. The present material conforms well to the original description of the species, except that two to three setae are present on the female pre-genital 

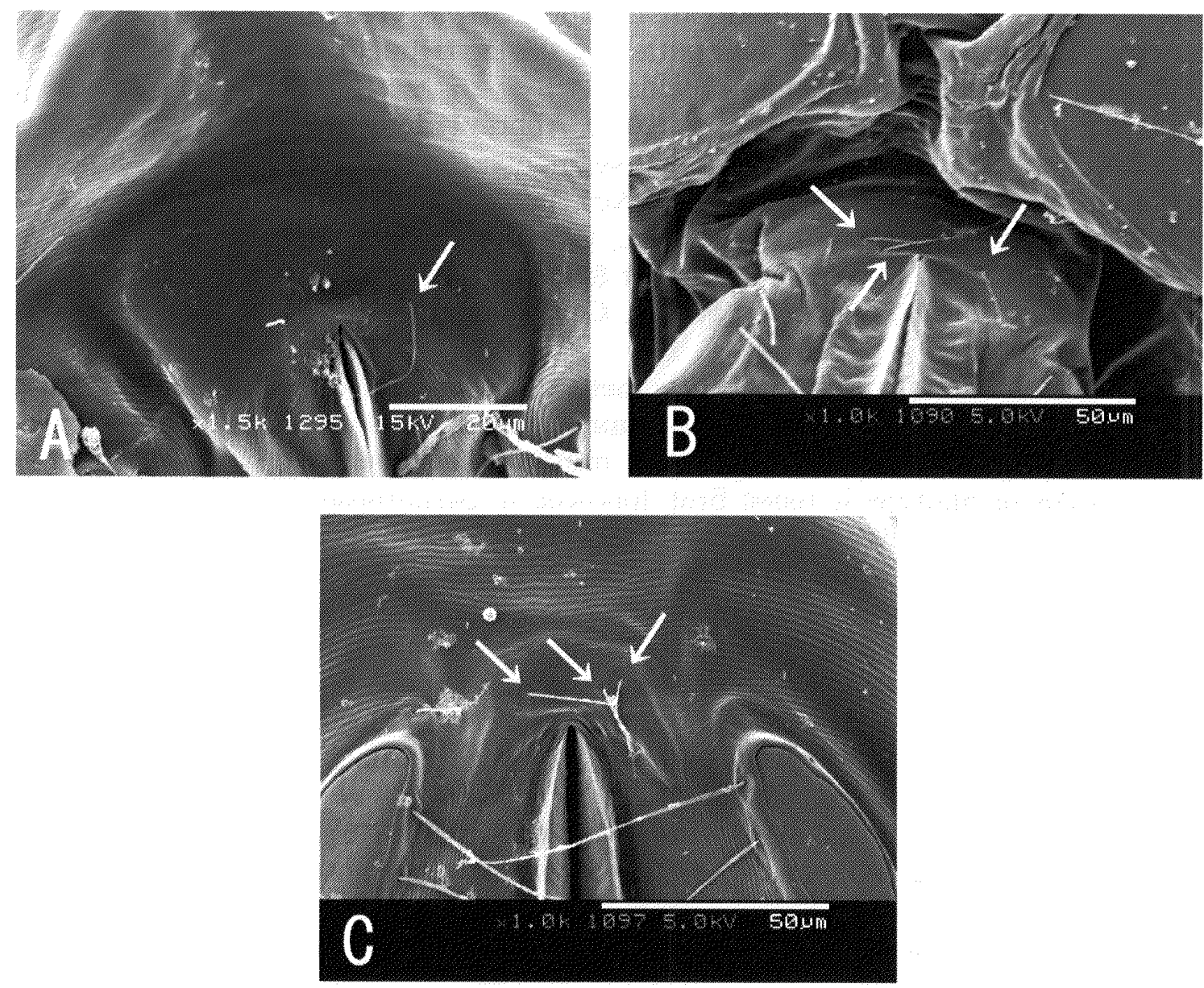

Fig. 2. SEM images of female pre-genital sclerite. A, Hygrobates (Hygrobates) biwaensis; B, $H$. $(H$.) rarus; $\mathrm{C}, H$. (H.) capillus sp. nov. Arrows indicate setae on the female pre genital sclerite.

sclerite in all the specimens observed (Fig. 2A). The present specimens were taken at a depth of $70 \mathrm{~cm}$ on a peddle shore, whereas Tuzovskij's (2003) material was collected at depths of $0.6-2 \mathrm{~m}$ among stones and sand.

\section{Hygrobates (Hygrobates) rarus Tuzovskij, 2003}

(Fig. 2B)

Hygrobates (Hygrobates) rarus Tuzovskij, 2003: 1329-1333, figs 5-7.

Type locality. Kitakomatsu, Lake Biwa (Tuzovskij 2003).

Material examined. All specimens were collected from Lake Biwa at the mouth of the Inugami River, Hikone, Shiga Prefecture, on 8 Oct. 2000. Three males (ZIHU-3146, NSMT-Ac 11876, LBM Misc. Invert. FY2004-14) and four females (ZIHU3147, 3148, NSMT-Ac 11877, LBM Misc. Invert. FY2004-14), dissected and mounted in polyvinyl alcohol. Two males (ZIHU-3149, 3150) and one female (ZIHU-3151), dissected and mounted in Euparal ${ }^{\mathbb{B}}$. One female (ZIHU-3152), metal-coated for SEM. 
Remarks. The present material accords well with the original description, except for having two or three setae upon the female pre-genital sclerite (Fig. 2B), which were not mentioned in the original description. The present specimens were collected at a depth of $40 \mathrm{~cm}$ on the sandy bottom of the river mouth, whereas Tuzovskij's (2003) specimens were taken from depths of $2-8.9 \mathrm{~m}$ among sand and stones.

\section{Hygrobates (Hygrobates) capillus sp. nov.}

(Figs 2C, 3, 4; Table 1)

Type locality. Kizu River, Kyotanabe, Kyoto, Japan.

Etymology. The specific epithet is derived from the Latin capillus (having setae), in reference to the setae on the female pre-genital sclerite.

Material examined. Holotype: female (ZIHU-3153), from type locality, 29 Feb. 2000, dissected and mounted in Euparal ${ }^{*}$. Allotype: male (ZIHU-3154), from type locality, 29 Feb. 2000, dissected and mounted in Euparal ${ }^{\mathrm{R}}$. Paratypes: two females (ZIHU-3155, LBM Misc. Invert. FY2004-13), from type locality, 07 Dec. 2000, dissected and mounted in polyvinyl alcohol; one female (NMST-Ac 11878) and two males (NMST-Ac 11879, LBM Misc. Invert. FY2004-13), from type locality, 29 Feb. 2000, one female (ZIHU-3156) and one male (ZIHU-3157), from the Koza River, Kozagawa, Wakayama Prefecture, 11 Mar. 2004, one male (ZIHU-3158), from the Kumano River, Hongu, Wakayama Prefecture, 09 Mar. 2004, and one female (ZIHU-3159), from the Nabari River, Nabari, Mie Prefecture, 08 Dec. 2000, all dissected and mounted in Euparal ${ }^{\text {s; }}$; one female (ZIHU-3160), from the Kumano River, Hongu, Wakayama Prefecture, 09 Mar. 2004, metal-coated for SEM. All specimens were collected by N. Matsumoto.

Description. Female. Idiosoma spherical, W $505(475,408-603, \mathrm{n}=4)$. Integument soft, with very fine striation. Coxoglandularia II (Fig. 3D) without secondary sclerotization. Antenniform setae thickened, each located on small, rounded base (Fig. 3E), L $42(44,39-48, n=3)$. Without dorsalia. Chelicera (Fig. 3C) with total L 267 (269, 248-303, $\mathrm{n}=4)$, maximum $\mathrm{H} 58(59,42-68, \mathrm{n}=4)$, L of basal segment 180 (184, $167-213, \mathrm{n}=4)$, L of claw $87(85,81-90, \mathrm{n}=4), \mathrm{L} / \mathrm{H}$ ratio $4.6(4.6,4.0-5.5, \mathrm{n}=4)$, basal segment/claw ratio $2.1(2.2,2.0-2.4, \mathrm{n}=4)$. Palp (Fig. 3B) with total L $345(369$, $332-425, \quad \mathrm{n}=4) . \mathrm{L} / \mathrm{H}$ of P-1 $29 / 32(29 / 35, \quad 26-35 / 32-39, \quad \mathrm{n}=4), \quad \mathrm{P}-2 \quad 90 / 52 \quad(98 / 60$, 90-109/52-68, $\mathrm{n}=4), \quad$ P-3 68/48 (70/47, 58-81/45-48, $\mathrm{n}=4), \quad$ P-4 109/39 (119/36, $109-138 / 32-39, \mathrm{n}=4), \mathrm{P}-548 / 16(52 / 17,48-61 / 16-18, \mathrm{n}=4)$. P-2 with truncate, roundedconical projection having $24(18,16-21, \mathrm{n}=4)$ denticles distributed to base. Ventral margin of P-3 flat in outline, with $12(13,11-14, \mathrm{n}=4)$ denticles occupying about distal half of ventral side. P-4 with 2 setae on ventral side, outer one long and thick, and $9(8,8-9, n=4)$ setae on lateral and dorsal sides; P-4 setae ratio $0.14(0.13$, $0.10-0.14, n=4)$. P-5 with $3(3,3-3, n=4)$ setae. Capitulum (Fig. 3A) broadly fused with first coxae, W $104(85,75-104, n=4)$; anterior margin of each half of capitulum with deep, rounded notch. Coxae (Fig. 3A) with $\mathrm{L} / \mathrm{W}$ of anterior coxal group $240 / 318(248 / 341,233-279 / 267-467, \mathrm{n}=4), \mathrm{L} / \mathrm{W}$ of posterior coxal groups $246 / 207$ $(249 / 199,220-285 / 168-233, n=4)$. Posterior end of anterior coxal group roundedtruncate; posterolateral apodemes extending slightly beyond sclerotization, 123 $(123,104-149, n=4)$ from tip to tip. Suture line between CxI and capitulum irregu- 

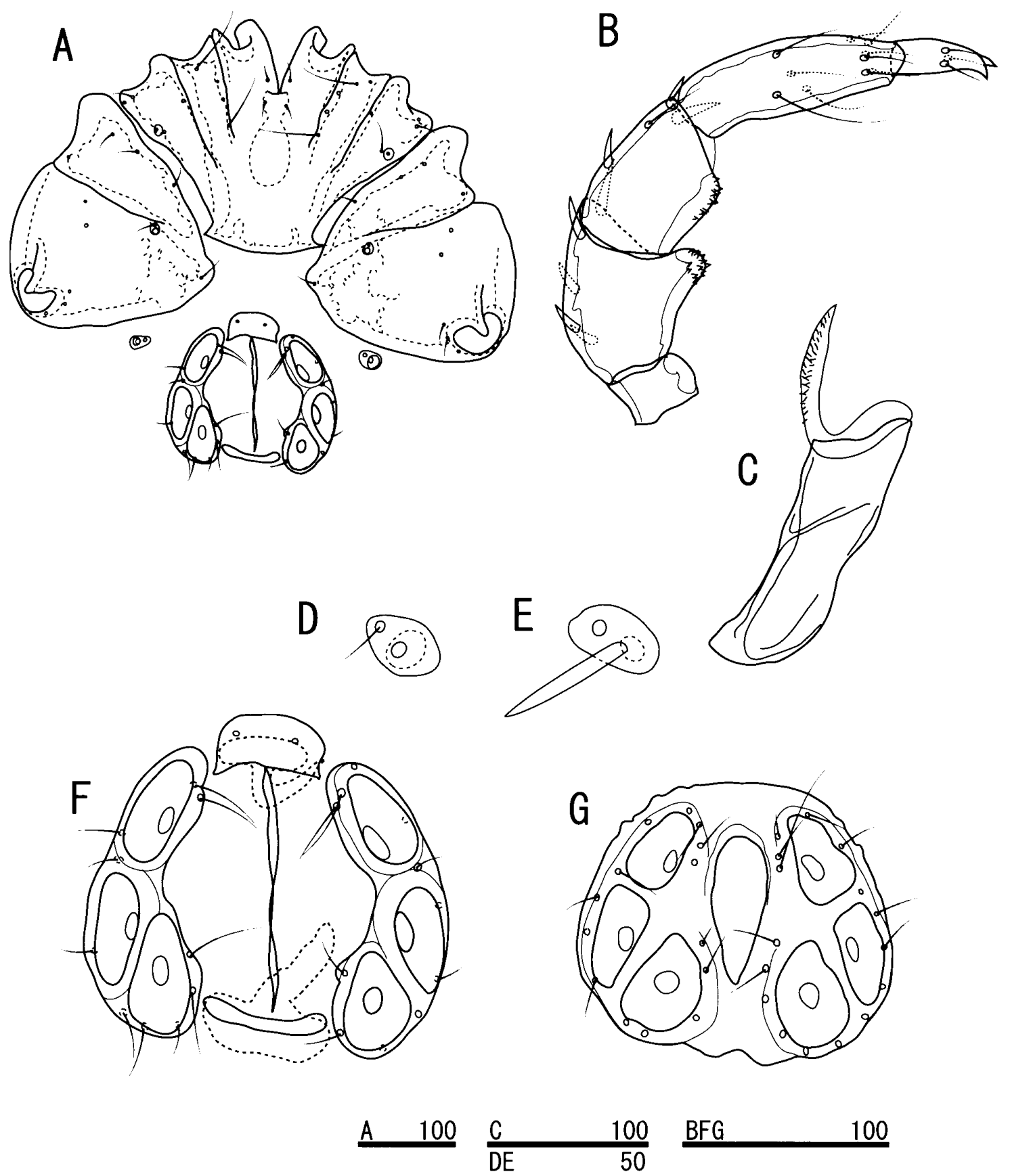

Fig. 3. Hygrobates (Hygrobates) capillus sp. nov. A-F, Female, holotype (ZIHU-3153); G, male, allotype (ZIHU-3154). A, Ventral side; B, palp; C, chelicera; D, coxoglandularia II; E, antenniform setae; F, genital fields; G, genital field. Scales in $\mu \mathrm{m}$.

lar, not curved. Coxoglandularium I on CxII. Suture line between CxIII and CxIV nearly straight, incomplete, extending to near glandularium of CxIV. Medial margin of CxIV rounded-triangular; angle apodemes lacking. Excretory pore without sclerotization. Legs (Fig. 4) lacking swimming hairs. Claws with ventral clawlet. Total L, from I-L to IV-L, 544/589/692/889 (580/650/798/970, 522-670/573-789/ 705-940/886-1137, n=4). Genital field (Figs 2C, 3F) with total W 175 (168, 149-194, 
Table 1. Lengths $(\mu \mathrm{m})$ of leg segments of Hygrobates $(H$.$) capillus sp. nov.$

\begin{tabular}{rllll}
\hline & \multicolumn{3}{c}{ Leg } \\
\cline { 2 - 5 } & \multicolumn{1}{c}{ I } & \multicolumn{1}{c}{ II } & \multicolumn{1}{c}{ III } & \multicolumn{1}{c}{ IV } \\
\hline Female & & & & \\
L-1 & $52,50,45-58^{\mathrm{a}}$ & $48,54,45-64$ & $55,62,55-74$ & $103,118,113-129$ \\
L-2 & $58,68,55-77$ & $61,73,61-87$ & $71,80,68-97$ & $93,104,93-122$ \\
L-3 & $81,91,81-106$ & $93,101,87-122$ & $106,118,103-142$ & $142,157,142-187$ \\
L-4 & $129,134,119-158$ & $135,151,132-184$ & $161,180,161-213$ & $196,215,193-258$ \\
L-5 & $132,136,126-158$ & $145,156,129-190$ & $180,199,180-235$ & $209,221,200-261$ \\
L-6 & $93,101,93-113$ & $106,115,97-142$ & $119,159,135-180$ & $145,155,145-180$ \\
Male & & & & \\
L-1 & $39,54,52-55$ & $48,57,52-61$ & $58,61,55-68$ & $106,104,97-109$ \\
L-2 & $71,73,64-81$ & $71,70,64-81$ & $84,82,77-87$ & $100,106,103-109$ \\
L-3 & $90,94,93-97$ & $97,107,103-113$ & $113,127,119-132$ & $151,164,155-174$ \\
L-4 & $135,137,129-145$ & $148,161,155-167$ & $177,193,184-203$ & $209,230,225-238$ \\
L-5 & $142,141,135-145$ & $161,175,167-180$ & $200,216,206-225$ & $225,241,232-251$ \\
L-6 & $103,106,103-109$ & $113,128,122-138$ & $145,158,145-167$ & $151,171,161-180$ \\
\hline
\end{tabular}

${ }^{a}$ Numerals represent the lengths of holotype (female) or allotype (male), and mean and range of paratypes $(n=4)$, respectively.

$\mathrm{n}=4)$. Acetabular plates with smooth border. Right genital plate with $10(12,11-13$, $\mathrm{n}=4)$ setae, left with $11(11,10-12, \mathrm{n}=4)$. Setae lacking on membranous integument near genital plate. $\mathrm{L} / \mathrm{W}$ of acetabular plates $149 / 58(140 / 55,123-172 / 45-65, \mathrm{n}=4)$. Genital acetabula arranged in arc. Distance between Ac1 and Ac2, and Ac2 and Ac3, less than W of Ac1. L/W of Ac1 52/19 (58/23, 39-81/21-29, n=4), Ac2 56/21 $(52 / 23,42-68 / 21-24, \mathrm{n}=4)$, Ac3 58/29 (51/29, 42-64/26-39, $\mathrm{n}=4)$. Pre- and postgenital sclerites with medially protruded apodemes. Two $(2,2-3, n=4)$ setae on pregenital sclerite. Anterior margin of pregenital sclerite located anterior to anterior margins of genital plates; postgenital sclerite situated, in its entirety, anterior to posterior margins of genital plates. Genital opening between pre- and postgenital sclerites, L $123(115,110-123, n=4)$. Excretory pore without sclerotization. L of leg segments as shown in Table 1.

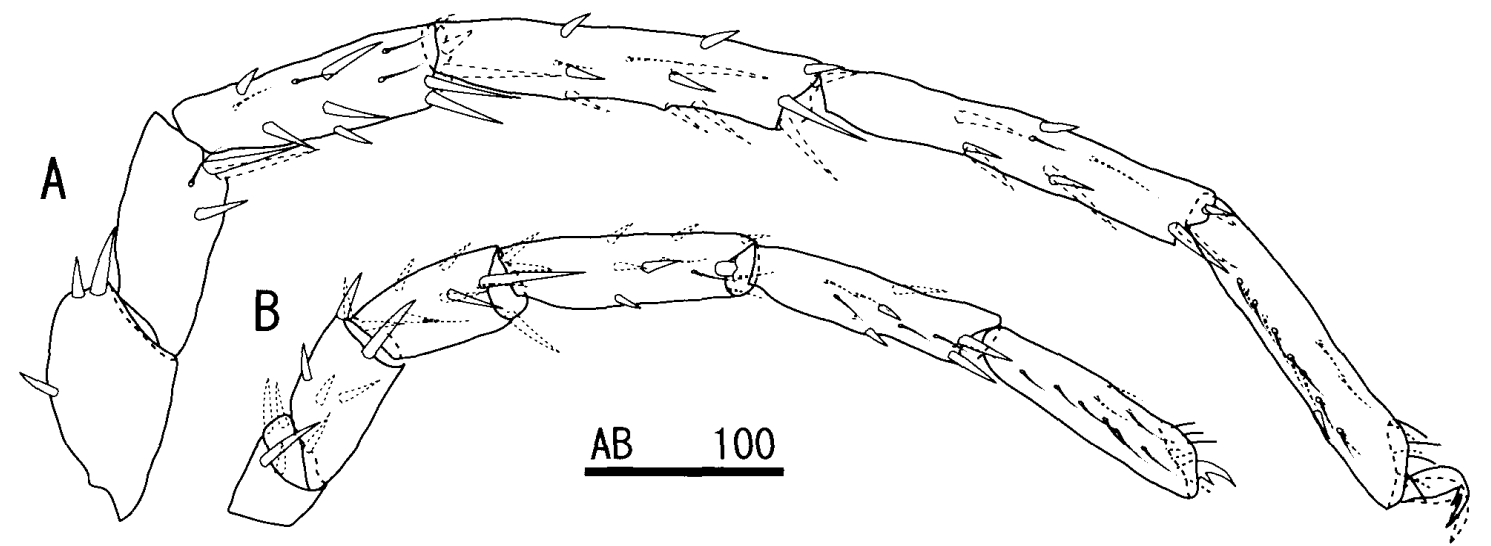

Fig. 4. Hygrobates (Hygrobates) capillus sp. nov., holotype (ZIHU-3153). A, Fourth leg; B, first leg. Scale in $\mu \mathrm{m}$. 
L ratios of II-L/I-L $1.1(1.1,1.1-1.2, \mathrm{n}=4)$, III-L/I-L $1.3(1.4,1.3-1.4, \mathrm{n}=4)$, IV-L/I-L $1.6(1.7,1.6-1.7, \mathrm{n}=4)$. Seta to L-5 ratio of I-L to IV-L $0.2 / 0.2 / 0.2 / 0.2(0.2 / 0.2 / 0.2 / 0.3$, $0.2-0.2 / 0.2-0.3 / 0.2-0.2 / 0.2-0.3, \mathrm{n}=4)$.

Male. Characters as in female, except for genital field. Idiosoma with W 525 $(564,538-603, \mathrm{n}=4)$. Antenniform setae with L $37(45,42-48, \mathrm{n}=2)$. Chelicera with total L $222(264,264-264, \mathrm{n}=3)$, maximum H $64(62,58-64, \mathrm{n}=3), \mathrm{L}$ of basal segment $138(182,177-193, \mathrm{n}=3)$, L of claw $84(83,71-87, \mathrm{n}=4), \mathrm{L} / \mathrm{H}$ ratio $3.5(4.3,4.1-4.6, \mathrm{n}=3)$, basal segment/claw ratio $1.7(2.3,2.0-2.7, \mathrm{n}=3)$. Palp with total L $348(366,348-380$, $\mathrm{n}=4)$. L/H of P-1 29/32 (25/32, 23-26/29-35, n=4), P-2 93/55 (98/60, 87-106/55-64, $\mathrm{n}=4)$, P-3 64/39 (68/44, 64-68/39-48, $\mathrm{n}=4), \mathrm{P}-4$ 113/23 (122/20, 116-126/16-23, $\mathrm{n}=4), \mathrm{P}-5$ 48/16 (52/16, 52-55/14-18, $\mathrm{n}=4)$. P-2 with $16(19,13-31, \mathrm{n}=4)$ denticles. P-3 with $13(17$, $13-24, \mathrm{n}=4)$ denticles. $\mathrm{P}-4$ with 2 setae on ventral side and $9(9,8-9, \mathrm{n}=4)$ setae on lateral and dorsal sides; P-4 setae ratio $0.11(0.13,0.13-0.14, \mathrm{n}=4)$. P-5 with 3 setae. Capitulum with W $84(92,84-97, \mathrm{n}=4)$. Coxae with $\mathrm{L} / \mathrm{W}$ of anterior coxal group $240 / 298(266 / 311,256-298 / 298-324, \mathrm{n}=4), \mathrm{L} / \mathrm{W}$ of posterior coxal groups $246 / 201$ $(279 / 222,266-298 / 214-240, \mathrm{n}=4)$. Posterolateral apodemes of anterior coxal group $110(120,110-130, \mathrm{n}=4)$ from tip to tip. Genital field (Fig. 3G) with total L/W 130/156 $(159 / 174,156-162 / 172-175, \mathrm{n}=4)$. Genital plate with otherwise smooth outer border irregularly wrinkled at anterolateral edge, with secondary sclerotization; anterior margin nearly straight; posterior margin with median notch; apodemes lacking. Acetabular plate with $14(15,14-18, n=4)$ setae on right side and $16(15,14-15, n=4)$ on left. Genital acetabula arranged in arc. Distance between Ac1 and Ac2, and Ac2 and Ac3, less than W of Acl. L/W of Ac1 45/29 (53/30, 52-55/29-32, n=4), Ac2 52/23 $(64 / 25,61-68 / 19-29, \mathrm{n}=4)$, Ac3 55/35 (67/38, 64-76/32-45, $\mathrm{n}=4)$. Total L of legs I-L to IV-L 580/638/776/943 (605/699/837/1016, 586-628/673-734/789-879/982-1063, $\mathrm{n}=4)$ ). L of leg segments as shown in Table 1. L ratios of II-L/I-L $1.1(1.2,1.1-1.2, \mathrm{n}=4)$, III-L/IL $1.3(1.4,1.3-1.4, \mathrm{n}=4)$, IV-L/I-L $1.7(1.7,1.7-1.7, \mathrm{n}=4)$. Seta to tibia ratio of I-L to IVL $0.2 / 0.2 / 0.2 / 0.2(0.2 / 0.2 / 0.2 / 0.2,0.2-0.2 / 0.2-0.2 / 0.2-0.2 / 0.2-0.3, \mathrm{n}=4)$.

Remarks. Hygrobates (Hygrobates) capillus sp. nov. is similar to $H$. (H.) biwaensis and $H$. $(H$.) rarus (cf. Tuzovskij 2003). These three species share the following characters, by which they also can be distinguished easily from the other members of the subgenus Hygrobates: 1) a long and thick ventro-lateral seta in the middle of P-4, and 2) two or three setae upon, and inside the margin of, the female pregenital sclerite.

Hygrobates $(H$.$) capillus can be distinguished from H$. (H.) biwaensis and $H$. $(H$.$) rarus by the following characters (the states of the latter two species are given,$ successively, in parenthesis): 1) P-2 ventral projection truncate (elongate, truncate), 2) female genital plates longer (shorter, shorter) than length of genital opening, 3) posterior end of female genital plates posterior (anterior, anterior) to postgenital sclerite, 4) anterior border of male genital plate flat (curved, curved), and 5) body size large (small, small) (Table 2).

Discussion. Some species of the subgenus Hygrobates have been reported to bear setae near (but not "on") the female pre-genital sclerite. Lundblad (1942) illustrated a pair of setae a short distance antero-lateral, or lateral, to this sclerite in $H$. (H.) discrepans Lundblad, 1930; H. $(H$.$) gracilidens Lundblad, 1936; H. (H$.$) plau-$ manni Lundblad, 1936; and H. (H.) plicatus Lundblad, 1942. Cook (1980) depicted the same pair of setae immediately adjoining and antero-lateral to the female pre-genital sclerite in $H$. (H.) corkelus Cook, 1980. 
Table 2. Means (ranges) of body sizes $(\mu \mathrm{m})$ in males and females of three species of Hygrobates; for each species, five specimens of each sex were measured.

\begin{tabular}{lccc}
\hline & H. $($ H.) biwaensis & H. $($ H.) rarus & H. (H.) capillus sp. nov. ${ }^{\mathrm{a}}$ \\
\hline Male & $373(337-408)$ & $343(305-363)$ & $556(525-603)$ \\
Female & $345(324-369)$ & $362(337-376)$ & $481(408603)$ \\
\hline
\end{tabular}

${ }^{\text {a }}$ Measurements for this species include holotype and allotype.

These setae were neither described nor illustrated in the original descriptions of $H$. (H.) biwaensis and $H$. (H.) rarus (cf. Tuzovskij 2003). In the present study, however, it was confirmed that both of these species, as well as $H$. $(H$.) capillus, bear several setae "on" (i.e., inside the margin of) the female pre-genital sclerite (Figs $2 \mathrm{~A}-\mathrm{C}, 3 \mathrm{G})$, a character state not previously reported for members of the subgenus Hygrobates.

In the description of their new species $H$. salamandrarum, Goldschmidt et al. (2002) reported "sieve disks", enigmatic structures visible only with SEM observation, on the membranous integument near the lateral sides of the female pre-genital sclerite. Because several setae were found on the periphery of the sieve disks, the authors suggested that special attention should be paid to this area in species bearing any seta near the female pre-genital sclerite. However, our SEM observation of this area showed no unusual features on the membranous integument (Fig. $2 \mathrm{~A}-\mathrm{C})$.

\section{Acknowledgments}

We wish to thank Dr. Yasuhiro Takemon (Kyoto University), Dr. Kazumi Tanida (Osaka Prefectural University), and Mr. Hironori Furuno (Osaka Prefectural University) for their help in collecting the present material; Dr. Shozo Ehara (Tottori City) for his constructive criticism; Dr. Tom Goldschmidt (Universität Karlsruhe), who kindly donated some European Hygrobates samples to the first author and commented on a draft of this paper; and Dr. Haruo Katakura (Hokkaido University), Dr. Matthew H. Dick (Hokkaido University), and Dr. Mark J. Grygier (Lake Biwa Museum) for their critical reading of the manuscript and valuable advice.

\section{References}

Cook, D. R. 1974. Water mite genera and subgenera. Memoirs of the American Entomological Institute 21: i-vii +1-860.

Cook, D. R. 1980. Studies on neotropical water mites. Memoirs of the American Entomological Institute 31: $\mathrm{i}-\mathrm{v}+1-645$.

Enami, M. 1940. Water mites from Izu I. Rheophilous water-mites from River Inozawa. Science Reports of the Tohoku Imperial University, Fourth Series, Biology 15: 203-259.

Goldschmidt, T., Gerecke, R. and Alberti, G. 2002. Hygrobates salamandrarum sp. nov. (Acari, Hydrachnidia, Hygrobatidae) from China: the first record of a freshwater mite parasitiz- 
ing newts (Amphibia, Urodela). Zoologischer Anzeiger 241: 297-304.

Imamura, T. 1950. On the life-history of a water-mite, Hygrobates longipalpis (Herm.). Gakugei 2: 74-78. [In Japanese]

Imamura, T. 1953a. Some water-mites from Hiroshima Prefecture. Journal of the Faculty of Science, Hokkaido University, Series VI, Zoology 11: 193-260.

Imamura, T. 1953b. Water-mites from Gifu Prefecture. Journal of the Faculty of Science, Hokkaido University, Series VI, Zoology 11: 411-471.

Imamura, T. 1954. Studies on water-mites from Hokkaido. Journal of Hokkaido Gakugei University, Section B, Supplement 1: 1-148.

Imamura, T. 1955. Crenophilous and rheophilous water-mites from Mishima and its vicinity. Bulletin of the Biogeographical Society of Japan 16-19: 181-192.

Imamura, T. 1960. Water-mites from the River Hinuma. Bulletin of the Faculty of Arts and Sciences, Ibaraki University, Natural Science 11: 39-52.

Imamura, T. 1965. Hydrachnellae. Pp. 216-251. In: Sasa, M. (Ed.) Mites, an Introduction to Classification, Bionomics and Control of Acarina. University of Tokyo Press, Tokyo. [In Japanese]

Imamura, T. 1980. Hygrobatidae. Pp. 348-353. In: Ehara, S. (Ed.) Illustrations of the Mites and Ticks of Japan. Zenkoku Noson Kyoiku Kyokai, Tokyo. [In Japanese]

Imamura, T. 1986. Acarina Hydrachnellae. Pp. 368-395. In: Uéno, M. (Ed.) The Late Tamiji Kawamura Freshwater Biology of Japan Enlarged and Revised Edition. Hokuryukan Publishing, Tokyo. [In Japanese]

Imamura, T. and Kikuchi, Y. 1986. Studies on water mites and harpacticoid copepods as the indicative animals for environmental factors in inland water habitats. Research Projects in Review, Nissan Science Foundation 8: 317-331. [In Japanese]

Lundblad, O. 1942. Die Hydracarinenfauna Südbrasiliens und Paraguays. Svenska Vetenskapsakademiens Handlingar 20: 3-174, Taf. I-VII.

Smith, I. M., Cook, D. R. and Smith, B. P. 2001. Water mites (Hydrachnida) and other arachnids. Pp. 551-659. In: Thorp, J. H. and Covich, A. P. (Eds) Ecology and Classification of North American Freshwater Invertebrates. 2nd Edition. Academic Press, San Diego.

Tuzovskij, P. V. 2003. Description of three new water mites species of the genus Hygrobates (Acariformes, Hygrobatidae). Zoologicheskii Zhurnal 82: 1325-1338. [In Russian with English summary]

Tuzovskij, P. V. and Gerecke, R. 2003. A new diagnosis and status for Mixobates Thor, 1905 (Acari, Hydrachnidia, Hygrobatidae), with a revision of the palaearctic species. Annales de Limnologie 39: 151-174.

Uchida, T. 1931. Einige Wassermilben aus Japan. Zoologischer Anzeiger 95: 262-268.

Uchida, T. 1934. Some rheophilous water-mites from Japan. Journal of the Faculty of Science, Hokkaido University, Series VI, Zoology 3: 67-116.

Viets, K. O. 1987. Die Milben des Süsswassers (Hydrachnellae und Halacaridae [part.], Acari) 2, Katalog. Paul Parey, Hamburg and Berlin, 1012 pp. 